\title{
Expression of CD44, CD44v9, ABCG2, CD24, Bmi-1 and ALDH1 in stage I and II oral squamous cell carcinoma and their association with clinicopathological factors
}

\author{
TETSUYA TAMATANI, NATSUMI TAKAMARU, GO OHE, KAZUYA AKITA, \\ TAKAYUKI NAKAGAWA and YOUJI MIYAMOTO \\ Department of Oral Surgery, Institute of Biomedical Sciences, \\ Tokushima University Graduate School, Tokushima 770-8504, Japan
}

Received September 18, 2017; Accepted April 11, 2018

DOI: $10.3892 / \mathrm{ol} .2018 .8703$

\begin{abstract}
Cancer stem cells (CSCs) exhibit self-replication, self-differentiation, drug resistance and immune evasion activities. In recent years CSCs have become increasingly important for the treatment of malignant tumors. CSCs express specific markers, including cluster of differentiation (CD)44, CD44 variant 9 (CD44v9), ATP-binding cassette sub-family G member 2 (ABCG2), CD24, B lymphoma Mo-MLV insertion region 1 homolog (BMI-1) and aldehyde dehydrogenase 1 (ALDH1). However, the prognostic value of their expression in patients with oral squamous cell carcinoma (OSCC) are not well known. The present study evaluated these markers in stage I and II patients with OSCC and examined the association between $\mathrm{T}$ classification, histological differentiation, classification of invasion mode, lymph node metastasis and disease-free survival rate. Tissue specimens were obtained from 70 patients with stage I or II OSCC following either surgery or biopsy. Immunohistochemistry was performed and positive staining was defiend as $10 \%$ positive cells. CD44 and CD44v9 expressions were strongly detected in all OSCC tissues compared with normal epithelial cells. A total of 22 (31.4\%) cases expressed ABCG2 and there was a significant association between ABCG2 expression and invasion. A total of 41 cases $(59.0 \%)$ expressed CD24 and there was a significant association between CD24 expression and invasion. A total of 33 cases $(47.1 \%)$ expressed BMI-1 and there was a significant association between BMI-1 expression and the disease-free survival rate. A total of 18 cases (25.7\%) expressed ALDH1.
\end{abstract}

Correspondence to: Dr Tetsuya Tamatani, Department of Oral Surgery, Institute of Biomedical Sciences, Tokushima University Graduate School, 3 Kuramoto-cho, Tokushima 770-8504, Japan E-mail: ttama@tokushima-u.ac.jp

Key words: cluster of differentiation 44, cluster of differentiation 44 variant 9, ATP-binding cassette sub-family G member 2, cluster of differentiation 24, B lymphoma Mo-MLV insertion region 1 homolog, aldehyde dehydrogenase 1 , oral cancer
Although there was no association between ALDH1 expression and $\mathrm{T}$ classification, there were significant associations between ALDH1 expression and histological differentiation, invasion mode, metastasis and the disease-free survival rate. Multivariate analysis revealed that ALDH1 expression was the only prognostic factor for disease-free survival rate. The results of the present study suggest that the positivity of ALDH1 detected in patients with OSCC correlates with the number of cells undergoing epithelial mesenchymal transition and metastasis. These findings indicated that the expression of ALDH1 may be an effective prognostic marker indicating the survival of patients with stage I and II OSCC.

\section{Introduction}

Cancer stem cells (CSCs) are functionally defined by their extensive self-renewal capacity. CSC confers increased radioand chemoresistance in tumors, resulting in tumor recurrence and metastatic spread. Therefore, identification of the regulators that control the tumorigenic potential of CSCs might provide new therapeutic strategies against CSCs to improve cancer treatment. The CSC theory suggests that only a few cancer cells with a capacity for high tumorigenicity, self-renewal, and differentiation are responsible for the maintenance and growth of tumors. Similar to normal tissue stem cells, CSCs can also exist within a supportive niche (1).

Oral squamous cell carcinoma (OSCC) patients in stage I and II are mainly treated by surgery and almost all patients show good prognosis, with a 5-year disease free survival rate of early stage OSCC patients over $90 \%$. However, approximately $10 \%$ of these early stage OSCC patients showed poor prognosis (2) and some cases have shown cervical lymph node metastasis and distant metastasis, with poor outcome. Currently, there are no prognostic markers for these stage I and II OSCC patients who show poor prognosis.

Cluster of differentiation (CD)44 is a cell surface transmembrane glycoprotein encoded by the CD44 gene, which consists of 20 exons. The standard isoform of CD44 is encoded by exons 1-5 and exons 16-20, and other CD44 variant $(\mathrm{CD} 44 \mathrm{v})$ protein isoforms are generated by alternative splicing with variable exons (3). CD44 functions in various 
biological processes, such as cell adhesion, cell migration, and cancer metastasis. More recently, CD44 has been recognized as a CSC marker in several types of cancers (3). However, as CD44 is ubiquitously expressed in many cell types, its usefulness as a CSC marker may be limited. Furthermore, conflicting data in the field implicate the importance of CD44 in both tumor suppression and progression, and these discrepancies have been largely attributed to the expression of alternatively spliced variants. Among the variants, CD44 variant 9 (CD44v9) may contribute to cancer survival in harsh environments, such as high reactive oxygen species-generated conditions from chemotherapy and/or radiotherapy (4-6).

ATP-binding cassette sub-family G member 2 (ABCG2) is a member of the ATP-binding cassette transporter protein superfamily that produces multiple drug-resistant cancers (7) and is a molecular determinant for maintaining the side population phenotype in stem cells. This phenotype has been isolated from several primary tumors and cancer cell lines, including those of the lung, esophagus, nasopharynx, and oral cavity (8-10). Furthermore, ABCG2 expression has been found in solid tumors of hepatocellular, lung, pancreas, and head and neck squamous carcinomas (HNSCC) (8-10). ABCG2 plays a critical role in the maintenance of the stem cell phenotype and multidrug resistance of cancer cells (7). ABCG2 also regulates the pattern of cell division in non-small cell lung cancer cell lines (9). A recent study suggested that the ABCG2-positive side population cells with the ability to exclude Hoechst 33342 and the possession of cancer stem-like properties may play an important role in oral carcinogenesis (9). Increasing evidence suggests $\mathrm{ABCG} 2$ is a marker in CSC and plays a central role in tumorigenesis (8-10).

CD24 is a mucin-like cell surface protein that is expressed in cells of the hematopoietic system, in neuronal tissues, and in certain epithelial cells such as keratinocytes $(11,12)$. Several studies have investigated CD24 expression in various malignant tissues; B cell lymphoma, lung, pancreatic, colorectal, breast, and prostate cancer (13-15). Although its physiologic functions are not fully elucidated, it seems to be involved in the regulation of tumor proliferation and adhesion. In cancer cells, the function of CD24 as a ligand for P-selection may be important for the metastatic potential of the tumors by facilitating interactions with endothelial cells. Previous studies showed that elevation of $\mathrm{CD} 24$ expression in various malignant tumors is associated with prognosis (12-15).

B-cell specific Moloney leukemia virus insert site 1 (BMI-1) is an essential constituent of polycomb repressive complex 1, a key epigenetic regulator. BMI-1 controls the cell cycle and the self-renewal of tissue stem cells by regulating chromatin and histone structure, and has been implicated in maintaining the self-renewal of neural, hematopoietic, and intestinal stem cells. Elevated Bmi-1 expression was demonstrated to be associated with dysplastic cell transformation during oral carcinogenesis and to be required for cancer cell replication and survival (16-18).

Aldehyde dehydrogenase 1 (ALDH1) contributes to the oxidation of retinol acid in early stem cell differentiation and also correlates with the number of cells undergoing epithelial-mesenchymal transition, a process that is considered a key for the formation of metastasis $(19,20)$. Several studies proposed ALDH1 as a putative marker for the identification and isolation of CSCs in many kinds of cancers including HNSCC $(19,21,22)$. Little is known regarding the biology or behavior of CD44, CD44V9, ABCG2, CD24, BMI-1, ALDH1 of stage I and II OSCC. We would choose those CSC marker among many reports considered important for survival rates including esophageal, lung, gastric, colorectal, and head and neck cancer $(1-19,21,22)$. And the significance of expression of those markers in stage I and II OSCC remains to be determined. In this study, we evaluated the association between expression of CSC markers and clinicopathological features of stage I and II OSCC patients and determined the potential correlation between CSC marker expression with clinical factors and prognosis. The aim of the present study was to clarify the prognostic factors for stage I and II OSCC patients focused on the expression of CSC markers. Because we need to find the prognostic factor in order to improve the poor outcome of approximately $10 \%$ of early stage OCC patients.

\section{Materials and methods}

Patients. Oral cancer tissues were obtained from 70 OSCC patients from Tokushima University Hospital at biopsy or surgery. Sixty eight cases were used biopsy samples except surgery samples of two cases. All patients were treated by surgery. Tumor size and clinicopathological stage of OSCC were classified according to the TNM staging system (2011). This study was approved by the Tokushima University Human Investigations Committee Febuary 2016. The Yamamoto-Kohama (YK) classification, which is a modified version of the classification of Jakobsson et al (23) and Willen et al (24), was used for pathological grade of tumor invasion (25). This classification has five grades (1, 2, 3, 4C and 4D) and focuses on the shape of tumor cell aggregation at the invasion front.

Immunohistochemistry: Samples were fixed in neutral $10 \%$ formalin and embedded in paraffin after resection. Sections (5 $\mu \mathrm{m}$-thick) were cut and transferred on slides; sections were deparaffinized in xylene and dehydrated in graded ethanol. Endogenous peroxidase activity was blocked by $1 \%$ hydrogen peroxide, and microwave antigen retrieval was carried out in a microwave oven. Immunostaining was performed using an avidin-biotin peroxidase enzyme complex (ABC kit; Vector Laboratories, Burlingame, CA, USA). The sections were incubated with monoclonal rabbit anti-human CD44 (clone EPR1013Y: dilution 1:100; Abcam, Cambridge, UK), monoclonal rat anti-human CD44v9 (LKG-M001: dilution 1:2,000; Funakoshi, Tokyo, Japan), monoclonal mouse anti-human ABCG2 (clone BXP-21: dilution 1:100; Abcam), monoclonal mouse anti-human CD24 (clone 8.B.76: dilution 1:50; Abcam), monoclonal mouse anti-human Bmi-1 (clone 1.T.21: dilution 1:100; Abcam), and monoclonal rabbit anti-human ALDH1 (clone EP1933Y: dilution 1:100; Abcam) antibodies overnight at $4^{\circ} \mathrm{C}$, and then subsequently placed in secondary anti-rabbit antibody followed by avidin-biotin complex reagent. The sections were finally incubated in the substrate 3,3'diaminobenzidine (0.05\%) and $0.1 \%$ hydrogen peroxide for $8 \mathrm{~min}$. The intensity of immunohistochemical staining was graded as negative and positive; expressions of CSC markers were considered positive when more than $10 \%$ of all tumor cells were stained. The grade of staining intensity 
Table I. Clinicopathological characteristics of the patients.

\begin{tabular}{|c|c|c|}
\hline Characteristic & Group & No. of patients \\
\hline \multirow[t]{2}{*}{ Sex } & Male & 34 \\
\hline & Female & 36 \\
\hline \multirow[t]{2}{*}{ Age (years) } & Median & 68 \\
\hline & Range & $35-97$ \\
\hline \multirow[t]{5}{*}{ Primary site } & Tongue & 38 \\
\hline & Oral floor & 5 \\
\hline & Upper gingiva & 5 \\
\hline & Lower gingiva & 16 \\
\hline & Buccal mucosa & 6 \\
\hline \multirow[t]{2}{*}{ T classification } & $\mathrm{T} 1$ & 17 \\
\hline & $\mathrm{T} 2$ & 53 \\
\hline \multirow[t]{3}{*}{ Histological type } & Well-differentiated & 35 \\
\hline & Moderately differentiated & 30 \\
\hline & Poorly differentiated & 3 \\
\hline \multirow[t]{5}{*}{ YK classification } & YK1 & 5 \\
\hline & YK2 & 24 \\
\hline & YK3 & 30 \\
\hline & YK4C & 6 \\
\hline & YK4D & 3 \\
\hline \multirow[t]{2}{*}{$\mathrm{N}$ status } & $\mathrm{N}(+)$ & 14 \\
\hline & $\mathrm{N}(-)$ & 56 \\
\hline
\end{tabular}

$\mathrm{N}$ status, occult cervical lymph node metastasis.

in case of different biomarkers were not taken into consideration in this study.

Statistical analysis. Statistical analysis was performed by Kruskal-Wallis test, Mann-Whitney $U$ test between expressions of CSC markers and clinicopathological factors. Survival analysis was calculated using the Kaplan-Meier Method and compared using the log-rank test. Cox hazard regression model was used for the multivariate analysis. The results were quantified using hazard ratio (HR) with $95 \%$ confidence interval $(95 \% \mathrm{CI}) . \mathrm{P}<0.05$ was considered to indicate a statistically significant difference.

\section{Results}

The expression of $C D 44, C D 44 v 9, A B C G 2, C D 24, B M I-1$, and $A L D H 1$ in OSCC with stage I and II. This study examined the expression of a panel of CSC markers in oral cancer tissues from 70 OSCC patients. The clinicopathological data of all patients are summarized in Table I. CD44 and CD44v9 protein expressions were detected in all OSCC tissues and were observed in the majority of tumor cells, as shown in Fig. 1 and Table II. CD44 and CD44v9 proteins were expressed in basal cell layer of normal oral epithelium and in more than $50 \%$ of the cells in epithelial dysplasia (data not shown). CD44 and CD44V9 proteins were localized to the plasma membrane and cytoplasm in cancer cells, and tended to exhibit intense irregular and disorganized staining patterns.
Table II. Expression rate of CSC marker.

\begin{tabular}{lcc}
\hline Marker & $\begin{array}{c}\text { No. of positive expression } \\
\text { patients/total patients }\end{array}$ & Percentage \\
\hline CD44 & $70 / 70$ & 100 \\
CD44V9 & $70 / 70$ & 100 \\
ABCG2 & $22 / 70$ & 31.4 \\
CD24 & $41 / 70$ & 59.0 \\
BMI-1 & $33 / 70$ & 47.1 \\
ALDH1 & $18 / 70$ & 25.7 \\
\hline
\end{tabular}

$\mathrm{CD}$, cluster of differentiation; OSCC, oral squamous cell carcinoma; BMI-1, B-cell-specific Moloney murine leukemia virus insertion site 1; ALDH1, aldehyde dehydrogenase 1; CSC, cancer stem cell.

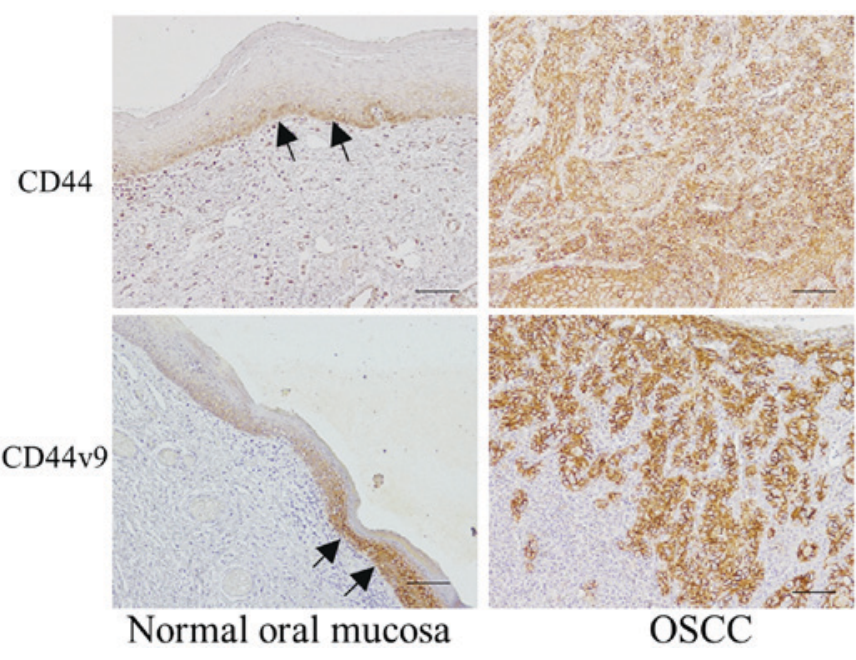

Figure 1. Representative figures of immunohistochemical staining for CD44 and CD44V9 in the oral mucosa of normal and OSCC tissues. The arrows show the basal cell layer. Scale bar, $100 \mu \mathrm{m}$. CD, cluster of differentiation; OSCC, oral squamous cell carcinoma.

The rates of ABCG2, CD24, BMI-1, and ALDH1 positive expression in OSCC patients were 31.4, 59.0, 47.1 and $25.7 \%$, respectively (Table II). Representative staining images of ABCG2, CD24, BMI-1, and ALDH1 proteins are presented in Fig. 2. ABCG2, CD24, BMI-1, and ALDH1 proteins were expressed in the plasma membrane and cytoplasm. ABCG2, CD24, and ALDH1 proteins were mainly localized in the invasive front. The well-differentiated cells forming keratin pearls tended to show expression of CD24 and BMI-1 proteins. ALDH1-positive cells were scattered and were notably absent in keratin pearls.

Correlation of CSC marker expressions and clinicopathologic characteristics. We next examined the correlation of CSC marker expressions with clinicopathologic features. Although ABCG2 expression was not associated with tumor size (Table III), histological differentiation, or lymph node metastasis, its expression was significantly associated with classification of invasion mode (YK classification) in OSCC. CD24 expression was not associated with tumor size, histological 
Table III. Statistical correlation of ABCG2 expression and clinicopathological features.

\begin{tabular}{llccr}
\hline Clinicopathological feature & \multicolumn{1}{c}{ Group } & ABCG2 (+) & ABCG2 (-) & P-value \\
\hline T classification & T1 & 6 & 11 & 0.71 \\
& T2 & 16 & 37 & \\
Histological type & Well-differentiated & 12 & 23 & 0.80 \\
& Moderately differentiated & 8 & 22 & \\
YK classification & Poorly differentiated & 1 & 2 & 0.04 \\
(invasion mode) & YK 1 & 1 & 4 & \\
& YK 2 & 12 & 12 & \\
& YK 3 & 3 & 27 & \\
& YK 4C & 3 & 1 & \\
N status & YK 4D & 2 & 7 & \\
& N (+) & 7 & 41 &
\end{tabular}

$\mathrm{N}$ status, occult cervical lymph node metastasis. ABCG2, ATP-binding cassette sub-family G member 2.

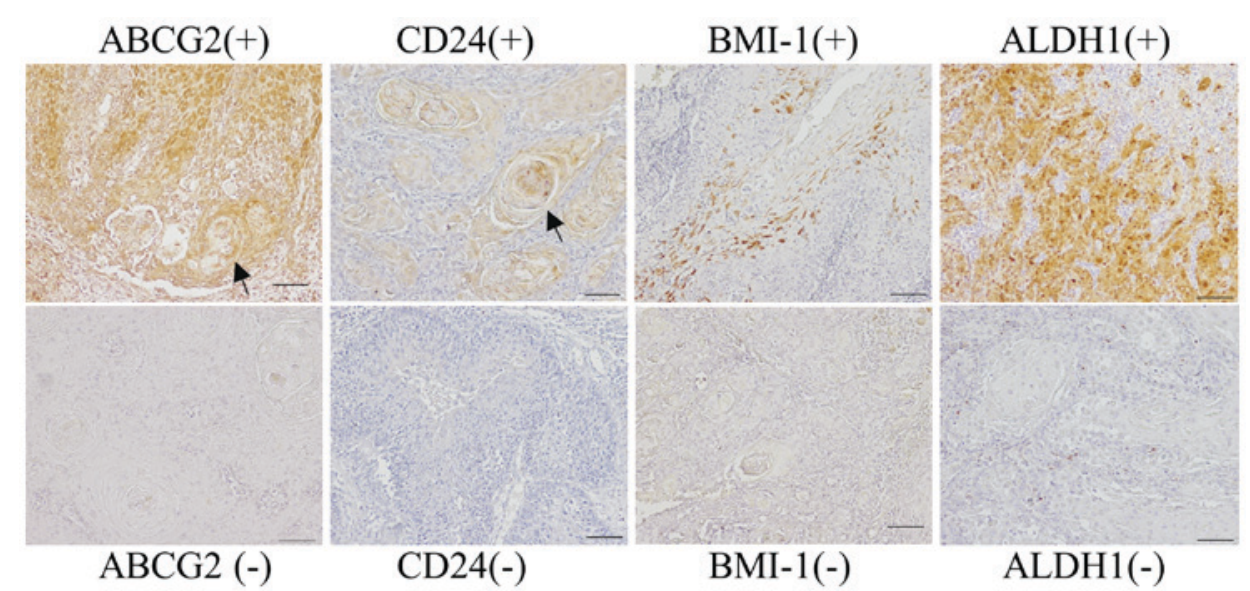

Figure 2. Representative figures of immunohistochemical positive and negative staining for ABCG, CD24, BMI-1, and ALDH1 in OSCC tissues. The arrows show the keratin pearls. Scale bar, $100 \mu \mathrm{m}$. CD, cluster of differentiation; OSCC, oral squamous cell carcinoma; BMI-1, B-cell-specific Moloney murine leukemia virus insertion site 1; ALDH1, aldehyde dehydrogenase 1; ABCG2, ATP-binding cassette sub-family G member 2.

differentiation, or lymph node metastasis (Table IV). However, there was an association between CD24 expression and invasion mode (YK classification). BMI-1 expression was not related with tumor size, histological differentiation, invasion mode (YK classification), or lymph node metastasis (Table V). There was significant association between ALDH1 expression and histological differentiation, invasion mode or lymph node metastasis (Table VI).

Survival analysis. We further determined the effects of the CSC marker expression in stage I and II OSCC patients on survival rate (Fig. 3). The data for overall survival are almost same of the data for disease free survival, because only one patients was died at other disease other than OSCC. So we could not show the data for overall survival. The expressions of ABCG2 or CD24 did not show an association with disease-free survival rate. Patients with BMI-1 expression showed better prognosis, and those who lacked BMI-1 expression showed worse prognosis. ALDH1 expression was significantly associated with worse prognosis. Multivariate analysis showed that ALDH1 expression was the only prognostic factor against disease-free survival rate (HR, 15.82, 95\% CI, 1.08-231.48, $\mathrm{P}=0.04$; Table VII).

\section{Discussion}

This study clearly demonstrated that there was significant association between ALDH1 expression and histological differentiation or invasion mode; ABCG2 expression and invasion mode; and CD24 expression and invasion mode in stage I and II OSCC patients. In addition, the expression of ALDH1 and lack of BMI-1 expression were significantly associated with survival in stage I and II OSCC patients.

We determined the expression of CD44 and CD44v9 in the oral mucosa and cancer tissues in 70 stage I and II OSCC patients. CD44 and CD44v9 expressions were almost in basal layer of normal epithelium and were abundantly expressed in most tumor cells. A previous study showed that CD44 
Table IV. Statistical correlation of CD24 expression and clinicopathological features.

\begin{tabular}{|c|c|c|c|c|}
\hline Clinicopathological feature & Group & CD24 (+) & CD24 (-) & P-value \\
\hline \multirow[t]{2}{*}{$\mathrm{T}$ classification } & $\mathrm{T} 1$ & 12 & 5 & 0.25 \\
\hline & $\mathrm{T} 2$ & 29 & 24 & \\
\hline \multirow[t]{3}{*}{ Histological type } & Well-differentiated & 24 & 11 & \\
\hline & Moderately differentiated & 15 & 15 & 0.21 \\
\hline & Poorly differentiated & 1 & 2 & \\
\hline \multirow{5}{*}{$\begin{array}{l}\text { YK classification } \\
\text { (invasion mode) }\end{array}$} & YK 1 & 5 & 0 & \\
\hline & YK 2 & 17 & 7 & \\
\hline & YK 3 & 12 & 18 & 0.03 \\
\hline & YK 4C & 3 & 1 & \\
\hline & YK 4D & 1 & 2 & \\
\hline \multirow[t]{2}{*}{ N status } & $\mathrm{N}(+)$ & 9 & 5 & 0.60 \\
\hline & N (-) & 32 & 24 & \\
\hline
\end{tabular}

$\mathrm{N}$ status, occult cervical lymph node metastasis. CD, cluster of differentiation.

Table V. Statistical correlation of BMI-1 expression and clinicopathological features.

\begin{tabular}{|c|c|c|c|c|}
\hline Clinicopathalogical feature & Group & BMI-1 (+) & BMI-1 (-) & P-value \\
\hline \multirow[t]{2}{*}{$\mathrm{T}$ classification } & $\mathrm{T} 1$ & 6 & 11 & 0.26 \\
\hline & $\mathrm{T} 2$ & 27 & 26 & \\
\hline \multirow[t]{3}{*}{ Histological type } & Well-differentiated & 17 & 18 & \\
\hline & Moderately differentiated & 15 & 15 & 0.25 \\
\hline & Poorly differentiated & 0 & 3 & \\
\hline YK classification & YK 1 & 3 & 2 & \\
\hline \multirow[t]{4}{*}{ (invasion mode) } & YK 2 & 12 & 12 & \\
\hline & YK 3 & 14 & 16 & 0.55 \\
\hline & YK 4C & 2 & 2 & \\
\hline & YK 4D & 0 & 3 & \\
\hline \multirow[t]{2}{*}{$\mathrm{N}$ status } & $\mathrm{N}(+)$ & 4 & 10 & 0.12 \\
\hline & N (-) & 29 & 27 & \\
\hline
\end{tabular}

N status, occult cervical lymph node metastasis. BMI-1, B-cell-specific Moloney murine leukemia virus insertion site 1.

expression was detected in $0.1-41.7 \%$ HNSCC cases (26). Sato et al found that increased expression of CD44v9 was significantly associated with poorer clinical outcome in OSCC (27). These findings are not in agreement with the results of this study showing that CD44 and CD44v9 were abundantly expressed in OSCC. Many reports investigated the CD44 expression rate (50 80\%) and relationship between CD44s expression and clinicopathological factors $(28,29)$. However, the results of these studies have been conflicting. Mack and Gires showed that the possibilities for these discrepancies may be due to different antibodies used, different cut-offs or different technologies used, i.e. flow cytometry (30). Clay et al recently suggested that it was unlikely that CD44+ cells were a pure population of CSCs, and highlighted the need for its evaluation in combination with another marker (31). This study showed that CD44 could not be an important biomarker for stage I and II OSCC.
ABCG2 expression was observed in $31.4 \%$ of OSCC patients in this study, and our data indicates that ABCG2 expression is related with invasion mode and is not associated with tumor size, differentiation, metastasis, and survival rate. However, there were few reports associated with ABCG2 expression and cancer cell invasion. On the other hand, it has been shown that ABCG2 expression was associated with malignant transformation of oral leukoplakia (OL), oral lichen planus (OLP), or oral erythroplakia (OE) $(17,32,33)$. ABCG2 expression was observed in 36 of 103 patients with untransformed OL and 22 of 32 patients with malignant transformed OL (32). Additionally, ABCG2 expression was detected in 21 and $35 \%$ untransformed OLP and OE patients, respectively, and upon malignant transformation, expression rates markedly increased to 69 and $88 \%$, respectively $(17,33)$. Although additional experiments are needed to determine whether ABCG2-positive cells are CSCs in oral potentially malignant disorders, these patterns 
Table VI. Statistical correlation of ALDH1 expression and clinicopathological features.

\begin{tabular}{|c|c|c|c|c|}
\hline Clinicopathalogical feature & Group & ALDH1 (+) & ALDH1 (-) & P-value \\
\hline \multirow[t]{2}{*}{$\mathrm{T}$ classification } & $\mathrm{T} 1$ & 4 & 13 & 0.81 \\
\hline & $\mathrm{T} 2$ & 14 & 39 & \\
\hline \multirow[t]{3}{*}{ Histological type } & Well-differentiated & 7 & 28 & \\
\hline & Moderately differentiated & 8 & 22 & 0.01 \\
\hline & Poorly differentiated & 3 & 0 & \\
\hline \multirow{5}{*}{$\begin{array}{l}\text { YK classification } \\
\text { (invasion mode) }\end{array}$} & YK 1 & 0 & 5 & \\
\hline & YK 2 & 4 & 20 & \\
\hline & YK 3 & 9 & 21 & 0.04 \\
\hline & YK 4C & 3 & 1 & \\
\hline & YK 4D & 2 & 1 & \\
\hline \multirow[t]{2}{*}{$\mathrm{N}$ status } & $\mathrm{N}(+)$ & 7 & 7 & 0.02 \\
\hline & N (-) & 11 & 45 & \\
\hline
\end{tabular}

$\mathrm{N}$ status, occult cervical lymph node metastasis. ALDH1, aldehyde dehydrogenase 1 .

Table VII. Cox regression analysis of CSC marker expression and disease free survival.

\begin{tabular}{lrlc}
\hline Factor & HR & $(95 \% \mathrm{CI})$ & P-value \\
\hline Age & 0.99 & $(0.91-1.08)$ & 0.79 \\
Primary site & 0.71 & $(0.27-1.85)$ & 0.48 \\
Histological type & 0.85 & $(0.22-3.34)$ & 0.82 \\
YK classification & 3.09 & $(0.80-12.03)$ & 0.10 \\
ABCG2 & 0.56 & $(0.04-7.51)$ & 0.67 \\
CD24 & 0.83 & $(0.09-7.57)$ & 0.87 \\
BMI-1 & 1.85 & $(0.13-25.71)$ & 0.21 \\
ALDH1 & 15.82 & $(1.08-231.48)$ & 0.04 \\
\hline
\end{tabular}

$\mathrm{HR}$, harzard ratio; $\mathrm{CI}$, confidence interval; $\mathrm{CD}$, cluster of differentiation; OSCC, oral squamous cell carcinoma; BMI-1, B-cell-specific Moloney murine leukemia virus insertion site 1; ALDH1, aldehyde dehydrogenase 1; CSC, cancer stem cell.

of ABCG2 expression may reveal its potential as an early detection biomarker in precancerous lesions.

CD24 expressions seemed to be implicated in tumor cell proliferation, cell-cell interactions, adhesion, and decreased E-cadherin expression $(34,35)$. The relationship between CD24 expression and YK classification of OSCC observed in this study might be caused by the decreased E-cadherin expression induced through CD24 overexpression. In breast tumors, CD24 positive cancer cells can be spread more rapidly (36). CD24 is also considered a potential target for treatment, as previous studies showed that CD24-specific antibodies can inhibit the growth of human colorectal and pancreatic cancer cell lines $(19,34)$. These authors had suggested that the shift from the membranous CD24 localization to the cytoplasm found in well-differentiated tumors could reflect the transition of epithelial cells to a more invasive phenotype $(19,34)$. However, our study did not reveal any significant associations between CD24
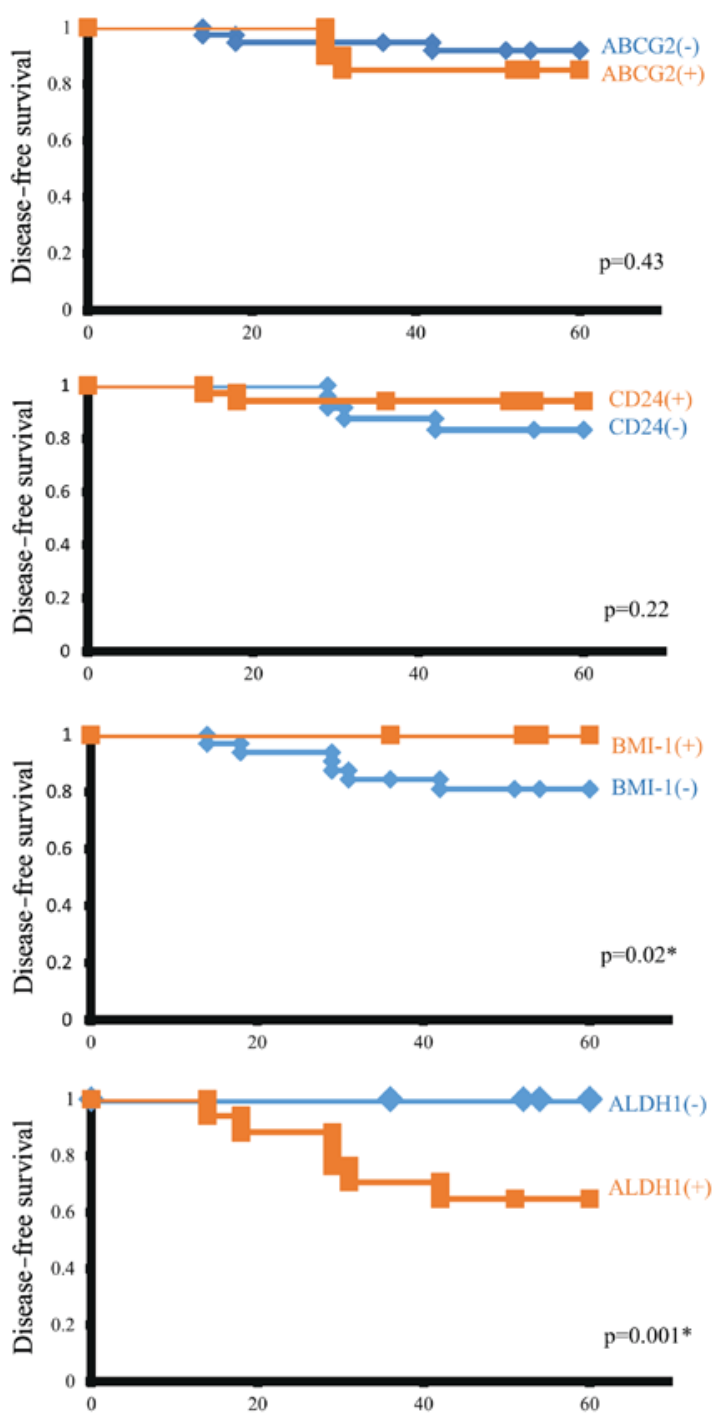

Figure 3. Disease-free survival curves according to AGCG2, CD24, BMI-1 and ALDH1 expression. The P-values were determined by log-rank test. $\mathrm{CD}$, cluster of differentiation; OSCC, oral squamous cell carcinoma; BMI-1, B-cell-specific Moloney murine leukemia virus insertion site 1; ALDH1, aldehyde dehydrogenase 1; ABCG2, ATP-binding cassette sub-family G member 2. 
expression and prognosis or other clinicopathologic features, and our results are consistent with other studies in OSCC $(12,32)$.

BMI-1 expression was not associated with tumor size, differentiation, invasion mode, or lymph node metastasis in this study. High BMI-1 overexpression was connected to poor prognosis in nasopharyngeal cancer, breast cancer and hepatocellular carcinoma $(16,18)$. In this study, BMI-1 expression in the OSCC patients led to better prognosis, but lack of BMI-1 expression was related with worse prognosis caused by distant metastasis. The reason was thought that the Bmi-1 expression would be related with distant metastasis of OSCC in this study. Several studies have shown that high BMI-1 expression was associated with poor prognosis $(16,18)$. However, Pietersen et al also reported a correlation between high expression of BMI-1 and better outcome in OSCC patients (26). These discrepancies may be due to the different types of epithelium in the population groups, the type of cancers, the population ethnicities, and differences in the underlying molecular mechanisms.

The present results show that ALDH1 was significantly associated with histological differentiation, invasion mode and lymph node metastasis. Moreover, multivariate analysis showed that ALDH1 expression was the only prognostic factor for disease-free survival rate. Overexpression of ALDH1 leads to increased cell proliferation and, notably, to increased resistance to chemotherapeutic agents (32). Several studies have reported an association between ALDH1-positive tumors and poor clinical prognosis in breast, lung, pancreatic, and prostate cancer (37). In this study, ALDH1 expression was observed in $25.7 \%$ of OSCC patients, which is similar as the ALDH1 expression rate compared with other cancers (37-39). We also found that increased ALDH1 expression correlated with poor disease-free survival of OSCC patients. However, contrasting results have also been reported. For instance, Chang et al reported that ALDH1 expression correlated with favorable prognosis in a group of ovarian cancer patients, which included 266 serous ovarian cancer patients and 176 non-serous ovarian cancer patients (38). In addition, Dimou et al reported that non-small cell lung cancer patients with high expression of ALDH1 had longer survival and lower recurrence rates (39). Thus, more prospective studies are needed to draw a definite conclusion. CSCs have major phenotype and functional heterogeneities, which may help distinguish them from cancer cells and may be of potential benefit in the development of anticancer therapies to improve clinical outcomes. Therefore, the present study supports the idea that ALDH1 could be a CSC marker, because of the significant correlation between ALDH1-positive OSCC patients and common clinical parameters, such as histological differentiation, invasion mode (YK classification), metastasis, and survival rate. The present findings suggested that ALDH1 positively in OSCC were likely to correlate with the number of cells undergoing epithelial mesenchymal transition and a process for the formation of metastasis.

We evaluated 68 biopsy samples and 2 surgery samples. However, biopsy tissues might not reflect the whole part of tumors. The present findings of this study might not be the results of CSC marker expression of the whole tumors. We should need to investigate the confirmation of this study.

In conclusion, our study indicated that the expression of ALDH1 could be an effective CSC marker to indicate the outcome of early stage OSCC patients.

\section{Acknowledgements}

Not applicable.

\section{Funding}

This study was supported in JSPS KAKENHI (grant no. $15 \mathrm{~K} 11294)$.

\section{Availability of data and materials}

The datasets analyzed during the current study are available from the corresponding author on reasonable request.

\section{Authors' contributions}

NT, GO, KA, and TN analyzed and interpreted the patient data. TT and YM performed the histological examination and TT was a major contributor in writing the manuscript. All authors read and approved the final manuscript.

\section{Ethics approval and consent}

This study was approved by the Ethics Committee of Tokushima University Hospital (approval no. 2516).

\section{Consent for publication}

Consent was obtained from all patients for the publication of their data.

\section{Competing interests}

The authors declare that they have no competing interests.

\section{References}

1. Mack B and Gires O: CD44s and CD44v6 expression in head and neck epithelia. PLoS One 3: e3360, 2008.

2. Yoshida Y, Sato K, Kin M, Suzuki T, Bessho H, Tanaka Y and Katakura: Relative factors of late cervical lymph node metastasis in patients with stage I or II oral squamous cell carcinoma. J oral Maxillo Surg Med Pathol 28: 156-161, 2016.

3. Okudela K, Woo T, Mitsui H, Tajiri M, Masuda M and Ohashi K: Expression of the potential cancer stem cell markers, CD133, CD44, ALDH1 and $\beta$-catenin, in primary lung adenocarcinoma-their prognostic significance. Pathol Int 62: 792-801, 2012.

4. Hirata K, Suzuki H, Imaeda H, Matsuzaki J, Tsugawa H, Nagano O, Asakura K, Saya H and Hibi T: CD44 variant 9 expression in primary early gastric cancer as a predictive marker for recurrence. Br J Cancer 109: 379-386, 2013.

5. Kimura Y, Goi T, Nakazawa T, Hirono Y, Katayama K, Urano T and Yamaguchi A: CD44variant exon 9 plays an important role in colon cancer initiating cells. Oncotarget 4: 785-791, 2013.

6. Go SI, Ko GH, Lee WS, Kim RB, Lee JH, Jeong SH, Lee YJ, Hong SC and Ha WS: CD44 Variant 9 serves as a poor prognostic marker in early gastric cancer, but not in advanced gastric cancer. Cancer Res Treat 48: 142-152, 2016.

7. Robey RW, To KK, Polgar O, Dohse M, Fetsch P, Dean M and Bates SE: ABCG2: A perspective. Adv Drug Deliv Rev 61: 3-13. 2009.

8. Bhagwandin VJ, Bishop JM, Wright WE and Shay JW: The Metastatic potential and chemoresistance of human pancreatic cancer stem cells. PLoS One 11: e0148807, 2016.

9. Tang Y, Hou J, Li G, Song Z, Li X, Yang C, Liu W, Hu Y and $\mathrm{Xu} \mathrm{Y}$ : ABCG2 regulates the pattern of self-renewing divisions in cisplatin-resistant non-small cell lung cancer cell lines. Oncol Rep 32: 2168-2174, 2014. 
10. Hoe SL, Tan LP, Jamal J, Peh SC, Ng CC, Zhang WC, Ahmad M and Khoo AS: Evaluation of stem-like side population cells in a recurrent nasopharyngeal carcinoma cell line. Cancer Cell Int 14: 101, 2014

11. Sano A, Kato H, Sakurai S, Sakai M, Tanaka N, Inose T, Saito K, Sohda M, Nakajima M, Nakajima T and Kuwano H: CD24 expression is a novel prognostic factor in esophageal squamous cell carcinoma. Ann Surg Oncol 16: 506-514, 2009.

12. Oliveira LR, Oliveira-Costa JP, Araujo IM, Soave DF, Zanetti JS, Soares FA, Zucoloto S and Ribeiro-Silva A: Cancer stem cell immunophenotypes in oral squamous cell carcinoma. J Oral Pathol Med 40: 135-142, 2011.

13. Kristiansen G, Winzer KJ, Mayordomo E, Bellach J, Schlüns K, Denkert C, Dahl E, Pilarsky C, Altevogt P, Guski H and Dietel M: CD24 expression is a new prognostic marker in breast cancer. Clin Cancer Res 9: 4906-4913, 2003.

14. Karahan N, Güney M, Oral B, Kapucuoglu N and Mungan T: $\mathrm{CD} 24$ expression is a poor prognostic marker in endometrial carcinoma. Eur J Gynaecol Oncol 27: 500-504, 2006.

15. Sagiv E, Starr A, Rozovski U, Khosravi R, Altevogt P, Wang T and Arber N: Targeting CD24 for treatment of colorectal and pancreatic cancer by monoclonal antibodies or small interfering RNA. Cancer Res 68: 2803-2812, 2008.

16. Choy B, Bandla S, Xia Y, Tan D, Pennathur A, Luketich JD, Godfrey TE, Peters JH, Sun J and Zhou Z: Clinicopathologic characteristics of high expression of Bmi-1 in esophageal adenocarcinoma and squamous cell carcinoma. BMC Gastroenterol 12: 146, 2012.

17. Feng JQ, Mi JG, Wu L, Ma LW, Shi LJ, Yang X, Liu W, Zhang CP and Zhou ZT: Expression of podoplanin and ABCG2 in oral erythroplakia correlate with oral cancer development. Oral Oncol 48: 848-852, 2012.

18. Allegra E, Caltabiano R, Amorosi A, Vasquez E, Garozzo A and Puzzo L: Expression of BMI1 and p16 in laryngeal squamous cel carcinoma. Head Neck 35: 847-851, 2013.

19. Goossens-Beumer IJ, Zeestraten EC, Benard A, Christen T, Reimers MS, Keijzer R, Sier CF, Liefers GJ, Morreau H, Putter $\mathrm{H}$, et al: Clinical prognostic value of combined analysis of Aldh1, Survivin and EpCAM expression in colorectal cancer. $\mathrm{Br}$ J Cancer 110: 2935-2944. 2014

20. Kahlert C, Bergmann F, Beck J, Welsch T, Mogler C, Herpel E, Dutta S, Niemietz T, Koch M and Weitz J: Low expression of aldehyde dehydrogenase 1A1 (ALDH1A1) is a prognostic marker for poor survival in pancreatic cancer. BMC Cancer 11: 275, 2011

21. Luo WR, Gao F, Li SY and Yao KT: Tumour budding and the expression of cancer stem cell marker aldehyde dehydrogenase 1 in nasopharyngeal carcinoma. Histopathology 61: 1072-1081, 2012.

22. Patel M, Lu L, Zander DS, Sreerama L, Coco D and Moreb JS ALDH1A1 and ALDH3A1 expression in lung cancers: Correlation with histologic type and potential precursors. Lung Cancer 59: 340-349, 2008.

23. Jakobsson PA, Eneroth CM, Killander D, Moberger G and Mårtensson B: Histologic classification and grading of malignancy in carcinoma of the larynx. Acta Radiol Ther Phys Biol 12: $1-8,1973$.

24. Willén R, Nathanson A, Moberger G and Anneroth G: Squamous cell carcinoma of the gingiva. Histological classification and grading of malignancy. Acta Otolaryngol 79: 146-154, 1975.

25. Yamamoto E, Miyakawa A and Kohama G: Mode of invasion and lymph node metastasis in squamous cell carcinoma of the oral cavity. Head Neck Surg 6: 938-947, 1984.
26. Prince ME, Sivanandan R, Kaczorowski A, Wolf GT, Kaplan MJ, Dalerba P, Weissman IL, Clarke MF and Ailles LE: Identification of a subpopulation of cells with cancer stem cell properties in head and neck squamous cell carcinoma. Proc Natl Acad Sci USA 104: 973-978, 2007.

27. Sato S, Miyauchi M, Takekoshi T, Zhao M, Kudo Y, Ogawa I, Kitagawa S, Fujita M and Takata T: Reduced expression of CD44 variant 9 is related to lymph node metastasis and poor survival in squamous cell carcinoma of tongue. Oral Oncol 36: 545-549, 2000.

28. Kokko LL, Hurme S, Maula SM, Alanen K, Grénman R, Kinnunen I and Ventelä S: Significance of site-specific prognosis of cancer stem cell marker CD44 in head and neck squamous-cell carcinoma. Oral Oncol 47: 510-516, 2011.

29. Huang CF, Xu XR, Wu TF, Sun ZJ and Zhang WF: Correlation of ALDH1, CD44, OCT4 and SOX2 in tongue squamous cell carcinoma and their association with disease progression and prognosis. J Oral Pathol Med 43: 492-498, 2014.

30. Mack B and Gires O: CD44s and CD44v6 expression in head and neck epithelia. PLoS One 3: e3360, 2008

31. Clay MR, Tabor M, Owen JH, Carey TE, Bradford CR, Wolf GT, Wicha MS and Prince ME: Single-marker identification of head and neck squamous cell carcinoma cancer stem cells with aldehyde dehydrogenase. Head Neck 32: 1195-1201, 2010.

32. Liu W, Feng JQ, Shen XM, Wang HY, Liu Y and Zhou ZT: Two stem cell markers, ATP-binding cassette, G2 subfamily (ABCG2) and BMI-1, predict the transformation of oral leukoplakia to cancer: A long-term follow-up study. Cancer 118: 1693-1700. 2012.

33. Shi P, Liu W, Zhou ZT, He QB and Jiang WW: Podoplanin and ABCG2: Malignant transformation risk markers for oral lichen planus. Cancer Epidemiol Biomarkers Prev 19: 844-849, 2010.

34. Choi D, Lee HW, Hur KY, Kim JJ, Park GS, Jang SH, Song YS, Jang KS and Paik SS: Cancer stem cell markers CD133 and CD24 correlate with invasiveness and differentiation in colorectal adenocarcinoma. World J Gastroenterol 15: 2258-2264. 2009.

35. Tanaka T, Terai Y, Kogata Y, Ashihara K, Maeda K, Fujiwara S, Yoo S, Tanaka Y, Tsunetoh S, Sasaki H, et al: CD24 expression as a marker for predicting clinical outcome and invasive activity in uterine cervical cancer. Oncol Rep 34: 2282-2228, 2015.

36. Li X, Kong X, Huo Q, Guo H, Yan S, Yuan C, Moran MS, Shao C and Yang Q: Metadherin enhances the invasiveness of breast cancer cells by inducing epithelial to mesenchymal transition. Cancer Sci 102: 1151-1157, 2011

37. Wakamatsu Y, Sakamoto N, Oo HZ, Naito Y, Uraoka N, Anami K, Sentani K, Oue N and Yasui W: Expression of cancer stem cell markers ALDH1, CD44 and CD133 in primary tumor and lymph node metastasis of gastric cancer. Pathol Int 62: 112-119, 2012.

38. Chang B, Liu G, Xue F, Rosen DG, Xiao L, Wang X and Liu J: ALDH1 expression correlates with favorable prognosis in ovarian cancers. Mod Pathol 22: 817-823. 2009.

39. Dimou A, Neumeister V, Agarwal S, Anagnostou V, Syrigos K and Rimm DL: Measurement of aldehyde dehydrogenase 1 expression defines a group with better prognosis in patients with non-small cell lung cancer. Am J Pathol 181: 1436-1442. 2012. 